\title{
Obstructive sleep apnea treated with custom-made bibloc and monobloc oral appliances: a retrospective comparative study
}

\author{
Göran Isacsson $^{1}$ (D) $\cdot$ Clara Fodor $^{1} \cdot$ Magnus Sturebrand $^{1}$
}

Received: 6 January 2016 / Revised: 6 June 2016 / Accepted: 28 June 2016 / Published online: 5 July 2016

(C) The Author(s) 2016. This article is published with open access at Springerlink.com

\begin{abstract}
Purpose The primary purpose of this hypothesis-generating retrospective study was to compare the effect of monobloc and bibloc (Narval $\left.{ }^{\mathrm{TM}}\right)$ appliances on the apnea-hypopnea index (AHI) and the total cost of treatment during the first year of treatment.

Methods Obstructive sleep apnea (OSA) subjects treated with a monobloc or bibloc during two different time periods were identified from medical records and data were extracted. Subjects treated with either of the appliances passed the same primary examination, follow-up visits, and follow-up polygraphic examination. A 1-year clinical follow-up was made on the bibloc group.

Results The study analysis included 110 monobloc- and 55 bibloc-treated subjects with baseline mean AHI of 23 and 22, respectively. AHI responders (AHI $<10$ and/or a $\geq 50 \%$ reduction of baseline $\mathrm{AHI}$ ) were seen at follow-up in $61 \%$ of the monobloc group and $56 \%$ of the bibloc group. The improvement of the AHI value was similar in the two groups, with mean declines of 12.7 and 13.8, respectively. The ODI (oxygen desaturation index), lowest $\mathrm{SpO}_{2}$, longest apnea, and the mean Epworth sleepiness scale (ESS) score were significantly reduced by 3.1 (monobloc) and 2.2 (bibloc), i.e., at the same level for both groups. The total direct cost of treatment for a 1-year treatment was $17 \%$ higher for the bibloc-treated subjects than for the monobloc-treated subjects.

Conclusions The results indicate that the monobloc and bibloc appliances are equally effective but the cost of
\end{abstract}

Göran Isacsson

goran.isacsson@1tv.se

1 Department of Orofacial Pain and Jaw Function, Västmanland County Hospital, Entrance 27, SE-721 89 Västerås, Sweden treatment over 1 year was higher with the bibloc. However, prospective randomized controlled trials are needed to adequately test the assumption that the two treatment modalities are equally effective.

Keywords Obstructive sleep apnea $\cdot$ Mandibular advancement device $\cdot$ Cost of treatment $\cdot$ Treatment outcome

\section{Introduction}

The oral appliance $(\mathrm{OA})$ is constructed so as to protrude the mandible during sleep and is a well-established treatment method of obstructive sleep apnea (OSA). The Food and Drug Administration (FDA) classifies intraoral appliances for snoring and/or OSA as class II (special controls) [1]. Oral appliances are indicated for use in patients with mild to moderate OSA who prefer them to continuous positive airway pressure (CPAP) therapy, or who do not respond to, are not appropriate candidates for, or who fail treatment attempts with CPAP [2]. A number of different designs of the OA are fabricated today, but there are two main types, namely the monobloc and the bibloc appliance. The former is a solid block of acrylic retained with clasps on the teeth and keeps the jaws in a fixed closed protruded position. The bibloc has separate constructions for the upper and lower jaws, equipped with connectors that protrude the mandible. The bibloc appliance allows the dentist to adjust the mandibular protrusion chairside, while the monobloc appliance requires the support of a dental technician. It is therefore assumed that the bibloc appliance should take less time to fit.

In a systematic review, Ahrens et al. [3] presented two studies comparing one-piece with two-piece appliances, in which no difference in reduction of AHI. These results are in contrast to the findings of a retrospective study by Lettieri 
et al. [4], who found significant advantages in AHI reduction with adjustable compared with fixed appliances. In a systematic review, Serra-Torres et al. [5] also concluded that adjustable and custom-made mandibular advancement appliances give better results than fixed and prefabricated appliances, and that monobloc appliances give rise to more adverse events.

At the beginning of 2011, the Narval ${ }^{\mathrm{TM}}$ bibloc appliance (hereafter, the bibloc appliance) was introduced to the Swedish market. The compliance, efficiency, side effects, and true cost of treatment for the bibloc in comparison with the commonly used monobloc appliance were not known. The primary purpose of this hypothesis-generating exploratory retrospective study was to compare the effect of monobloc and bibloc appliances on the apnea-hypopnea index (AHI), and the cost of treatment during the first year of treatment. A clinical- and questionnaire-based evaluation was also made on the bibloc-treated group after 1 year.

\section{Materials and methods}

\section{Subjects}

Subjects had an established diagnosis of OSA and had been referred to the Department of Orofacial Pain, Vastmanland Hospital, Västerås, for treatment with an oral appliance. All subjects, independent of subjective symptoms, who commenced treatment with monobloc appliances during the period January 2009 to May 2010, and all subjects who commenced treatment with bibloc appliances during the period January 2011 to January 2012 were included. The monobloc appliances were all fabricated by Boxholm Tandteknik ${ }^{1}$ and the bibloc appliances were manufactured by ResMed. ${ }^{2}$

Inclusion criteria were a diagnosis of OSA with $\mathrm{AHI} \geq 10$, and an oral status allowing retention of an appliance. Exclusion criteria were snoring without OSA, maximal protrusion of less than $5 \mathrm{~mm}$, and ongoing prosthodontic treatment.

The treatment in all phases including all technician costs for all subjects was covered by the national health security program (the annual cost for an adult person is at a maximum of $1100 \mathrm{skr}$ for all health services).

\section{Study procedure}

This is a clinical retrospective open effectiveness study describing polygraphic respiratory data and the cost of treatment for the year after the commencement of treatment with monobloc and bibloc appliances. All subjects treated with a monobloc appliance were contacted by mail to obtain their written informed consent to extract information from their

\footnotetext{
${ }^{1}$ Boxholm Tandteknik, Box 103, 59010 Boxholm, Sweden.

${ }^{2}$ ResMed Sweden AB, JanStenbecks Torg 17, 16440 Kista, Sweden.
}

medical records. No further clinical study examination of the monobloc group was made. Information was collected from the subjects' baseline data and during the year after commencing the treatment. Data from the bibloc group were gathered in the same way but the subjects were also invited to participate in a 1-year follow-up. The clinical management of all subjects, independent of type of appliance, was the same at primary examination, follow-up, and polygraphic examination at baseline and follow-up.

All subjects visited the clinic, where a baseline clinical examination was made and impressions of the jaws were taken. A protrusion index protruded the mandible to $60-80 \%$ of the maximal protrusion. Treatment commenced 2-3 weeks after the baseline examination and the appliance was fitted into the mouth. If the retention was insufficient or needed adjustment, it was returned to the technician for adjustment or redesign.

An evaluation visit was scheduled 1-2 months after the treatment commenced. Without any specified protocol, the subject was asked about snoring/apnea and the effect of the appliance and ESS score collected. If required, the appliance was adjusted. To adjust the degree of protrusion, the monobloc was returned to the technician together with a new protrusion index and an extra visit was then scheduled. Protrusion adjustment of the bibloc appliance was made chairside. If the subject experienced pain, discomfort, or problems with adapting to the appliance, individual considerations were made.

Polygraphy was performed with concomitant use of the appliance after the clinical evaluation. In cases of unsatisfactory respiratory values $(\mathrm{AHI}>10)$, the mandible was advanced if possible. Those who then had the appliance adjusted were subjected to additional polygraphy.

The bibloc appliance treatment subjects were invited to participate in a clinical follow-up examination and to respond to a questionnaire 1 year after treatment commenced.

\section{Somnopolygraphic examination}

Polygraphy was completed at the Department of Physiology, Vastmanland Hospital, Vasteras, as part of the clinical routine for the examination of sleep apnea. All subjects underwent a one-night respiratory baseline polygraphy (Embletta ${ }^{\circledR}$, ResMed) without any respiratory support. After 5-6 months of use of the appliance, the polygraphy was repeated with the appliance in place.

\section{Cost of treatment}

The calculation of a 1-year direct total cost of treatment for the payer (the County Council) was based on the appliance fabrication cost (technician cost) plus the dental office time, which was standardized to $1 \mathrm{~h}$ for the first visit, $30 \mathrm{~min}$ for the second visit (treatment start), and $30 \mathrm{~min}$ for the third visit (follow- 
up). All extra visits, including also those for dental laboratory adjustment of protrusion, were set at $30 \mathrm{~min}$ each. The cost of the dental office time was fixed at 2000 Swedish krona (SEK) (€216, \$235) per hour.

\section{One-year follow-up clinical examination and questionnaire}

A clinical examination was made at the 1-year follow-up of the bibloc appliance. The patient was asked to bite with a mild force. Occlusal stability in the intercuspal position was registered if the molar teeth could keep a firm grip on an occlusal foil; if not, it was classified as posterior open bite. Masseter and temporalis muscle palpation tenderness and pain with jaw movements were recorded with a yes/no response. The TMJ condylar movement, tenderness to palpation, and sound- and jaw movement-related pain were also registered as yes/no. The maximal mouth opening (distance between the incisors) and the maximal range of protrusion in the premolar region were measured.

The subjects completed a questionnaire with items on jaws, teeth, snoring, and sleepiness. In addition, sleepiness was also graded on an 11-point scale where $(0=$ no sleepiness; $10=$ worst imaginable sleepiness). The question "How important is the appliance for your and/or your bed partner's well-being" was measured using an 11-point Likert scale $(0=$ no importance; $10=$ greatest possible importance). Patients rated the change in their overall status since the beginning of the study treatment on the seven-point Patient Global Impression of Change (PGIC) scale ( $1=$ very much improved; $2=$ much improved; $3=$ minimally improved; $4=$ no change; $5=$ minimally worse; $6=$ much worse; $7=$ very much worse).

\section{Statistics}

Because of the exploratory and retrospective nature of the study, no power calculation was made. Instead, reasonable sized groups of subjects were included to allow proper hypothesis generation. The results were presented as descriptive statistics and tabulations. The primary variable was the difference between the baseline and follow-up polygraphic AHI value. Secondary variables were the cost of 1 year of treatment, adverse events, and other polygraphic measures.

The Uppsala Regional Ethical Review Board, Sweden approved the study 12th September 2012, \#2012/307. Informed consent was obtained from all subjects in both the mono- as well as the bibloc groups.

\section{Results}

During the defined period, 160 subjects had a monobloc appliance fitted. All but one subject (deceased) were sent a letter asking for informed consent to extract data from their medical records. Up to two follow-up letters were sent to those who did not initially respond. Figure 1 illustrates the recruitment flow for the 110 subjects who were included in the study analysis. Ninety percent of the subjects $(n=99)$ received an appliance made of hard acrylic and the remaining $10 \%$ received a soft elastomer appliance. During the defined period, 116 subjects had a bibloc appliance fitted (see Fig. 1). A total of 55 subjects were included in the study and visited the clinic for the 1-year follow-up.

The baseline demographics, mandibular movement range, and polygraphic data are described in Table 1 . The proportion of males was $79 \%$ in the monobloc group and $80 \%$ in the bibloc group. The age range was $31-82$ years $($ mean $=58)$ for the monobloc group, and $37-76$ years $($ mean $=57)$ for the bibloc group. The two treatment groups were similar in most baseline parameters except for the maximal protrusion range, and consequently the degree of mandibular advancement with the appliance. The bibloc appliance group had the mandible protruded $3 \mathrm{~mm}$ on average more than the monobloc group. CPAP treatment failure preceded $15 \%$ of treatment in the monobloc group and $8 \%$ in the bibloc appliance group. One subject in each group had been subjected to oropharyngeal surgery. The mean time from starting the bibloc treatment to the 1-year clinical follow-up ranged from 359 to 643 days with a mean of 481 days (16 months).

At the beginning of treatment, $95 \%$ of both the monobloc and bibloc appliances could be fitted into the mouth and jaws; the remaining $5 \%$ of appliances required technician support for adjustment or had to be remade.

At the evaluation visit, 11 subjects (10\%) in the monobloc group needed to have their appliance adjusted to better control the effect on apnea and/or snoring. These subjects were subjected to a new protrusion index and the technician adjusted the appliance accordingly. In the bibloc group, 21 subjects (38\%) had the length of the connector rod exchanged, thereby correcting the degree of protrusion. This was done chairside, without the support of a technician.

At the evaluation visit, $78 \%$ of the monobloc and $67 \%$ of the bibloc appliance-treated subjects were symptom free from the jaws and teeth. The remaining subjects had various symptoms as shown in Table 2.

The use of an oral appliance significantly improved the respiratory parameters in both appliance groups. The AHI score reduced by a mean of 12.7 and 13.8 for the monobloc and bibloc appliance groups, respectively. The daytime sleepiness score, measured by the ESS, was significantly reduced with the use of the appliances (Table 3).

Based on polygraphic data at follow-up, 57 subjects $(52 \%)$ in the monobloc group got an $\mathrm{AHI}<10$. Those with $\mathrm{AHI} \geq 10$ were recalled to the clinic and the mandibular protrusion was advanced if possible. As a consequence, 16 subjects had a second polygraphy, with an end result of 67 (61\%) AHI responders $(\mathrm{AHI}<10$ and/or $50 \%$ reduction of baseline AHI) registered (Fig. 2). 
Fig. 1 Recruitment schedule of the subjects treated with monobloc and bibloc appliances

\section{Monobloc group}

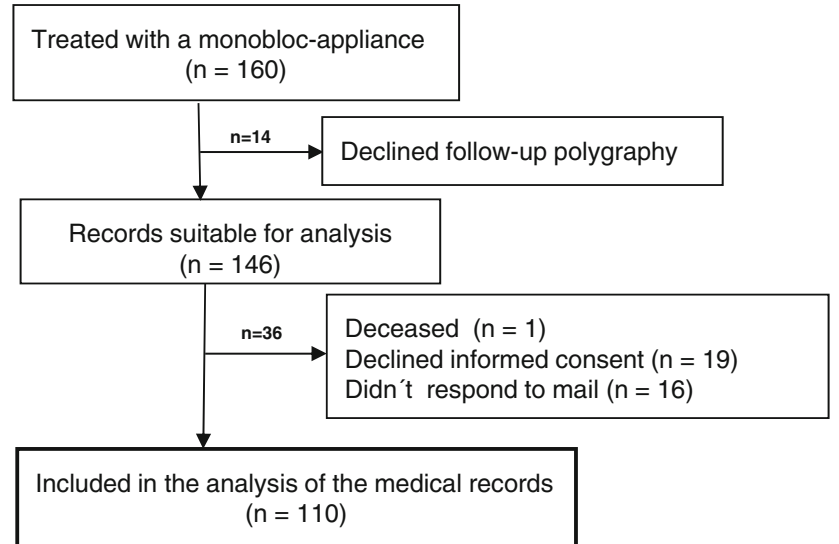

Bibloc group

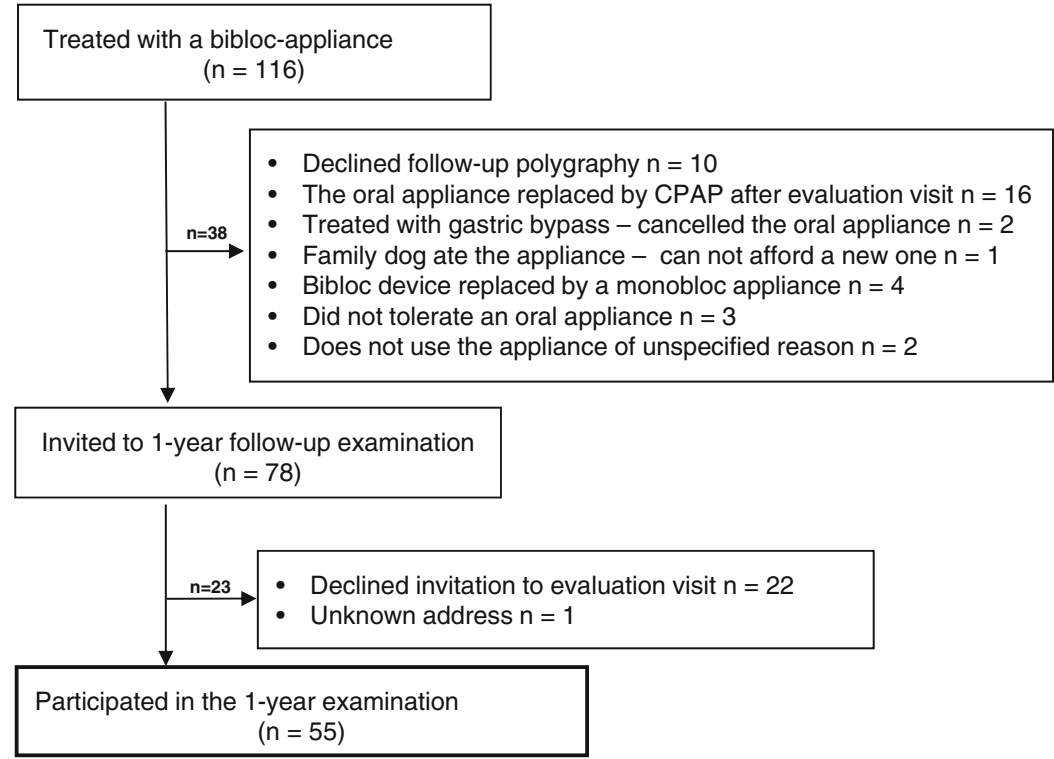

Polygraphic examination of the bibloc group revealed 30 subjects $(55 \%)$ with an $\mathrm{AHI}<10$ with four subjects referred for a second polygraphic examination. A total of 31 (56\%) were classified as AHI responders.

During the year after starting the appliance treatment, the number of extra visits to the clinic was 0-6 occasions for both groups (mean $=1.17$ for the monobloc group, 1.0 for the bibloc group). The total direct cost of treatment for the payer over 1 year could then be calculated as SEK $7270(€ 786$, \$854) for a monobloc-treated subject and SEK 8500 (€920, \$999) ( 17 \% higher) for a bibloc-treated subject (Table 4) To note, the fabrication cost was fixed independent from number of adjustments to be done by the technician.

At the 1-year follow-up, the predefined questions revealed that one third of the subjects had stiffness/tiredness of the jaws and one fifth had orofacial pain and difficulties fitting the teeth after waking up (Table 5). The mean score in response to the question "How important is the appliance for you/your bed partner's well-being" was 8.7 (SD 2.3) on the 11-point Likert scale $(0=$ no importance; $10=$ greatest possible importance) . The overall status at the 1-year follow-up since the beginning of treatment was rated at least "much improved" by $89 \%$ of the subjects and none of the subjects scored worse on the PGIC scale. At the 1-year clinical examination, the most common clinical sign was TMJ sound and masseter and temporalis muscle palpation tenderness. A posterior open bite occurred in four of the subjects (Table 6).

\section{Discussion}

The results of the present retrospective hypothesis-generating study indicate that the monobloc and bibloc appliances show 
Table 1 Baseline characteristics of subjects treated with a sleep apnea oral appliance

\begin{tabular}{lll}
\hline & $\begin{array}{l}\text { Monobloc appliance } \\
n=110 \\
\text { mean (SD) }\end{array}$ & $\begin{array}{l}\text { Bibloc appliance } \\
n=55 \\
\text { mean (SD) }\end{array}$ \\
\hline Subject characteristics & & \\
BMI & $28(4.6)$ & $28(4.2)$ \\
ESS & $11(5.1)$ & $10(4.2)$ \\
Characteristics of somnopolygraphy & & \\
ODI & $21(11.1)$ & $20(13.0)$ \\
AHI & $23(11.2)$ & $22(14.8)$ \\
Lowest SpO $2 \%)$ & $81(6.4)$ & $42(6.2)$ \\
Longest apnea (sec) & $46(20.0)$ & $12(2.8)$ \\
Characteristics of mandibular protrusion & & $9(2.1)$ \\
Maximal mandibular PTR range (mm) & $10(2.6)$ & $73(5.6)$ \\
Mandibular PTR with appliance (mm) & $6(2.0)$ & $67(9.0)$ \\
Proportion of appliance-guided PTR in relation to max PTR $(\%)$ & $62)$ \\
\hline
\end{tabular}

$B M I$ body mass index, ESS Epworth sleepiness scale, $O D I$ oxygen desaturation index, $A H I$ apnea hypopnea index, $\mathrm{SpO}_{2}$ oxygen saturation, $P T R$ protrusion the same level of efficiency in reducing apnea-hypopnea events, sleepiness, and the degree of side effects. There was one major difference, namely the cost of treatment, with the bibloc appliance being $\sim 17 \%$ more expensive than the monobloc appliance over 1 year. However, the results should be treated with caution for a number of reasons: the retrospective study design, the subjects were not recruited identically, the withdrawal rate was substantial, the study was not blinded and polygraphy was done and not polysomnograhpy, the adherence was not tracked, and the subjects were not randomly allocated to a treatment group.

Both the monobloc and bibloc appliances significantly reduced the AHI by a mean of about 12-14 events per hour, which is the same magnitude previously reported in both individual studies and systematic reviews [3, 6-8].

In a Cochrane meta-analysis, Lim et al. [9] analyzed crossover studies comparing active oral appliances with control appliances and found a reduction of AHI value by a mean of 15.15 events per hour. In parallel group studies, a mean reduction of 10.78 was noted. In studies comparing oral appliances with no treatment, the AHI improvement was a mean of 11 events per hour (95\% CI, 8-15) [10]. Vecchierini et al. [11] used Narval bibloc appliances in 369 OSA patients and found
AHI reduction means of 7, 15, and 25 for mild, moderate, and severe OSA, respectively. This highlights the importance of presenting efficacy data based on OSA severity.

In a systematic review, Ahrens et al. [3] presented two studies $[12,13]$ comparing one-piece with two-piece appliances, in which no difference in reduction of AHI was found. Rose et al. [13] compared the Silencer ${ }^{\circledR}$ Herbst-type appliance with a Karwetzky activator on patients with mild OSA in a crossover study. Both appliances reduced the RDI value by 9 and 11 events per hour, respectively. In a crossover study, Bloch et al. [12] evaluated a monobloc and a Herbst appliance in moderate OSA patients. Although the reduction of AHI was similar, with $14-15$ events per hour, the patients preferred the monobloc to the Herbst construction. These results are in contrast to the findings of a retrospective study by Lettieri et al. [4], who found significant advantages in AHI reduction with adjustable compared with fixed appliances. They also presented the results grouped by grade of severity and noted that in mild OSA, the effects of the two types of appliances were similar. In a systematic review, Serra-Torres et al. [5] concluded that adjustable and custom-made mandibular advancement appliances give better results than fixed and prefabricated appliances, and that monobloc appliances give rise to more
Table 2 Symptoms of the teeth/ jaw at the evaluation visit

\begin{tabular}{lll}
\hline & $\begin{array}{l}\text { Monobloc } \\
n=106\end{array}$ & $\begin{array}{l}\text { Bibloc } \\
n=55 \\
n(\%)\end{array}$ \\
& $n(\%)$ \\
\hline No subjective symptoms & $86(78)$ & $37(67)$ \\
A lesser degree of symptoms, which did not reduce the use of the appliance & $14(13)$ & $9(16)$ \\
Moderate degree of symptoms, which reduced the use of the appliance & $5(5)$ & $7(13)$ \\
Severe symptoms, which did not allow the use of the appliance & $1(1)$ & $2(4)$ \\
\hline
\end{tabular}


Table 3 Improved difference from baseline without any appliance vs. with the use of an appliance

\begin{tabular}{|c|c|c|c|c|c|c|}
\hline & \multicolumn{3}{|l|}{ Monobloc appliance } & \multicolumn{3}{|l|}{ Bibloc appliance } \\
\hline & Mean difference (SD) & $95 \% \mathrm{CI}$ & $p^{\mathrm{a}}$ & Mean difference (SD) & $95 \% \mathrm{CI}$ & $p^{\mathrm{a}}$ \\
\hline AHI & $12.7(11.6)$ & $10.5 ; 14.8$ & 0.000 & $13.8(14.8)$ & $9.8 ; 17.8$ & 0.000 \\
\hline AI & $8.3(9.1)$ & $6.6 ; 10.1$ & 0.000 & $8.0(1.6)$ & $4.8 ; 11.3$ & 0.000 \\
\hline ODI & $11.0(11.3)$ & $8.9 ; 13.2$ & 0.000 & $12.2(13.7)$ & $8.4 ; 16.1$ & 0.000 \\
\hline Lowest $\mathrm{SpO}_{2}(\%)$ & $3.0(6.1)$ & $1.7 ; 4.2$ & 0.000 & $2.1(5.6)$ & $0.5: 3.6$ & 0.000 \\
\hline Longest apnea (sec) & $15.2(19.4)$ & $11.1 ; 19.3$ & 0.000 & $11.0(20.0)$ & $5.0 ; 17.0)$ & 0.001 \\
\hline ESS & $3.1(4.0)$ & $2.2 ; 3.9$ & 0.000 & $2.6(4.3)$ & $1.0: 4.1$ & 0.002 \\
\hline
\end{tabular}

$A H I$ apnea hypopnea index, $A I$ apnea index, $O D I$ oxygen desaturation index, $\mathrm{SpO}_{2}$ oxygen saturation, ESS Epworth sleepiness scale

${ }^{\mathrm{a}} p$ value reflects the difference within the treatment group adverse events. Objective polygraphic registrations are crucial as described by Marklund et al. [14] who evaluated fixed OAs incrementally advanced in response to the clinical observation. Whether or not adjustable oral appliances improve the effect more than monobloc appliances remains uncertain and prospective randomized controlled trial evaluations are required.

In the present study, $61 \%$ percent of the monobloc group and $56 \%$ of the bibloc group were classified as responders. This is less than the $75 \%$ for monobloc and $67 \%$ responders
Fig. 2 Polygraphic outcome following treatment with monobloc and bibloc appliances

\section{Monobloc group}

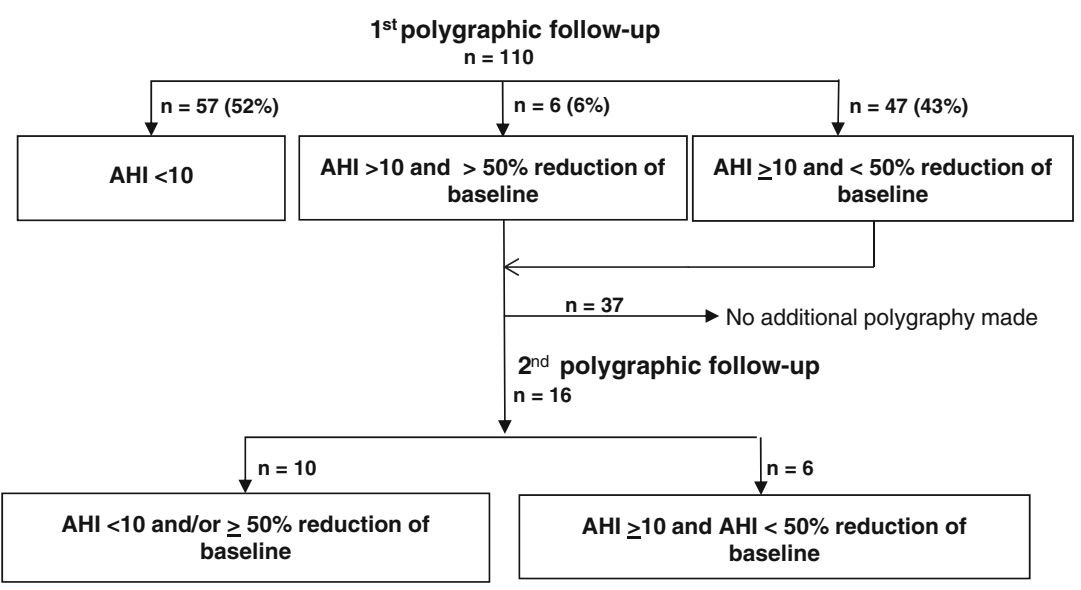

\section{Bibloc group}

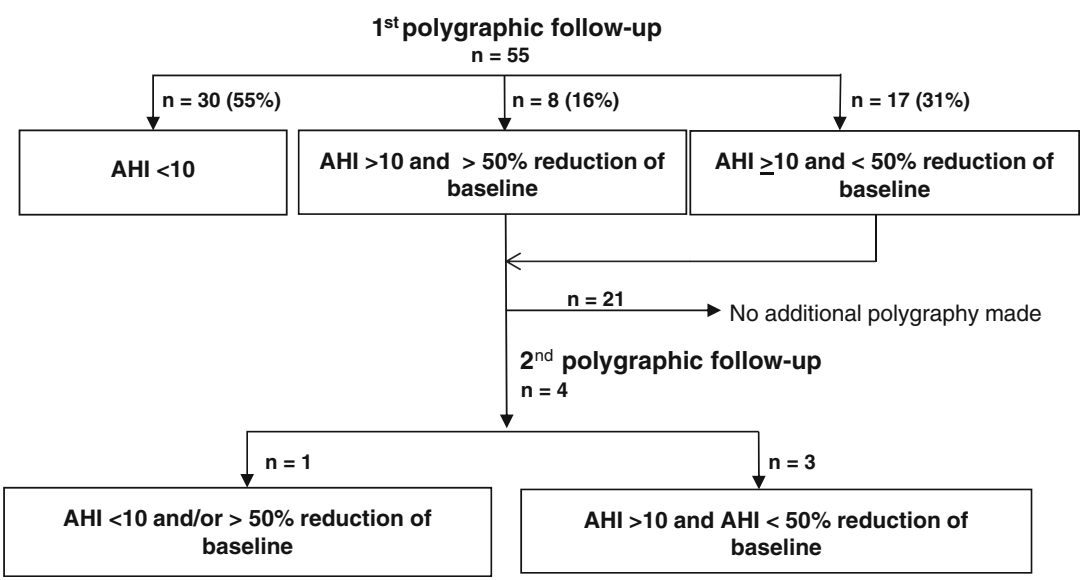


Table 4 The mean total treatment direct cost in Swedish crowns, skr, during one 1-year considering both the technician and dentist costs

\begin{tabular}{llllll}
\hline & $\begin{array}{l}\text { Fabricating } \\
\text { cost skr }\end{array}$ & $\begin{array}{l}\text { Cost for three } \\
\text { routine visits } \\
\text { at the dental } \\
\text { office }\end{array}$ & $\begin{array}{l}\text { Mean number } \\
\text { of extra visits } \\
\text { during a year }\end{array}$ & $\begin{array}{l}\text { Cost for extra visits } \\
\text { to the dental clinic }\end{array}$ & $\begin{array}{l}\text { Total cost } \\
\text { during a } \\
\text { year }\end{array}$ \\
\hline Monoblock & 2100 & 4000 & 1.17 & $1.17 * 0.5 * 2000=1170 \mathrm{skr}$ & $7270 \mathrm{skr}$ \\
Biblock & 3500 & 4000 & 1.0 & $1.0 * 0.5 * 2000=1000 \mathrm{skr}$ & $8500 \mathrm{skr}$ \\
\hline
\end{tabular}

${ }^{\mathrm{a}}$ Cost of dental office per hour was set to $2000 \mathrm{skr}$. Calculated dentist time - visit $1: 1 \mathrm{~h}$ for information, clinical examination, protrusion index, impression; visit $2: 0.5 \mathrm{~h}$ for fitting in the appliance; visit 3: $0.5 \mathrm{~h}$ for the follow-up, which sum up to $2 \mathrm{~h}$. All extra visits calculated to $30 \mathrm{~min}$ reported by Bloch et al. [12] for the Herbst bibloc appliance. The reason for the diverging results depends on a number of factors, including the severity of OSA, the degree of mandibular advancement, and the degree of vertical increase, as well as insufficient statistical power of the studies. Treatment effects tend to be greater in crossover trials than in parallel group studies, and the effects in trials of short duration are greater than in those in longer studies [15].

The ESS scores improved significantly in our study, with a mean reduction of 3.1 and 2.6 for the monobloc and bibloc groups, respectively. In a meta-analysis of randomized controlled parallel group studies, Lim et al. [9] compared active and controlled oral appliances showing an improvement of the ESS score by -2.09. Qaseem et al. [10] found that oral appliances improved the ESS score by 1.2 and 1.95 points, compared with no treatment and sham treatment, respectively. However, their meta-analysis did not include the more recent publication by Marklund et al. [16]. At a 4-month follow-up, they found that the ESS was significantly improved in both the active and the placebo appliance groups although the difference between the groups was not significant.

Martinez-Gomis et al. [17] followed patients using a Herbst-type bibloc appliance over 5 years and noticed that both symptoms and technical complications were more

Table 5 Positive response to a series of predefined questions on subjective symptoms at 1 -year follow-up by the 55 subjects treated with a bibloc appliance

\begin{tabular}{ll}
\hline & $n(\%)$ \\
\hline Stiffness/tiredness of the jaws & $19(35)$ \\
Difficulty in opening the mouth or chewing & $6(11)$ \\
TMJ sounds at chewing & $10(18)$ \\
Orofacial pain & $11(20)$ \\
Difficulty fitting the teeth after waking up & $12(22)$ \\
Difficulty fitting the teeth in the daytime & $2(4)$ \\
Disturbed by my own snoring & $4(7)$ \\
My snoring disturbs others & $18(33)$ \\
Disturbed/woken up by my own apnea & $2(4)$ \\
Bed partner worried about my apnea & $3(6)$ \\
Usually wake up during the night & $35(64)$ \\
\hline
\end{tabular}

frequent during the first year of treatment, with a mean of 3.0 unscheduled visits. In our study, means of 1.17 and 1.0 extra visits were found for the monobloc and bibloc appliance groups, respectively. Although the difference in unscheduled visits may depend on differences in the strength of the constructions, it certainly depends on the variation in routine at the clinic and perhaps the variation in the primary advancement of the mandible at the start of the treatment. A potentially higher threshold for adjusting a monobloc appliance may also affect the number of visits. The timeframe for the cost analysis in the present study was only 1 year and of course the devices durability over a number of years may affect the cost in any direction. In Lim et al.'s Cochrane study [9], participants given the active oral appliance suffered side effects more frequently than those given the control appliance. In our study, one third responded that they had tiredness/stiffness of the jaws that frequently created difficulties in fitting their teeth after waking up. The most alarming objective finding of our study was the development of a posterior open bite in four of the 55 bibloc-treated patients after 1 year (the monobloc group did not go through a 1 -year clinical follow-up). This highlights the need for a regular clinical check when mandibular advancement appliances are used.

The results of our study revealed a cost difference of SEK 1230 (GBP 95, \$145, €132) over 1 year between the monobloc and bibloc appliances. For the payer, the GBP 95 difference may be of some importance as the two types of appliances are equally effective.

Table 6 The outcome of the clinical examination at the 1-year followup of bibloc-appliance users, $n=55$

\begin{tabular}{|c|c|c|}
\hline & $\begin{array}{l}\text { One side } \\
n(\%)\end{array}$ & $\begin{array}{l}\text { Bilateral } \\
n(\%)\end{array}$ \\
\hline Posterior open bite & $3(6)$ & $1(2)$ \\
\hline $\begin{array}{l}\text { Masseter and temporalis muscle palpation } \\
\text { tenderness }\end{array}$ & $8(15)$ & $8(15)$ \\
\hline TMJ palpation tenderness & $1(2)$ & $4(7)$ \\
\hline Impaired translation of condyle & $2(4)$ & $2(4)$ \\
\hline TMJ sound & $9(16)$ & $5(9)$ \\
\hline TMJ pain at jaw movement & $2(4)$ & $2(4)$ \\
\hline Jaw muscle pain at jaw movement & $1(2)$ & $2(4)$ \\
\hline
\end{tabular}


Acknowledgments This study was supported by grants from the Uppsala-Örebro Regional Research Council and Vastmanland County Council.

\section{Compliance with ethical standards}

Conflict of interest The authors declare that they have no conflict of interest.

Ethical standards The study has been performed in accordance with the ethical standards laid down by the 1964 Declaration of Helsinki. The Uppsala Regional Ethical Review Board, Sweden approved the study on September 12, 2012 (\#2012/307). Informed consent was obtained from all subjects prior to inclusion.

Open Access This article is distributed under the terms of the Creative Commons Attribution 4.0 International License (http:// creativecommons.org/licenses/by/4.0/), which permits unrestricted use, distribution, and reproduction in any medium, provided you give appropriate credit to the original author(s) and the source, provide a link to the Creative Commons license, and indicate if changes were made.

\section{References}

1. Food, Drug Administration HHS (2002) Dental devices; classification for intraoral devices for snoring and/or obstructive sleep apnea. Final rule. Fed Regist 67(218):68510-68512

2. Kushida CA, Morgenthaler TI, Littner MR, Alessi CA, Bailey D, Coleman J Jr, Friedman L, Hirshkowitz M, Kapen S, Kramer M, Lee-Chiong T, Owens J, Pancer JP (2006) Practice parameters for the treatment of snoring and obstructive sleep apnea with oral appliances: an update for 2005. Sleep 29(2):240-243

3. Ahrens A, McGrath C, Hagg U (2011) A systematic review of the efficacy of oral appliance design in the management of obstructive sleep apnoea. Eur J Orthod 33(3):318-324. doi:10.1093/ejo/cjq079

4. Lettieri CJ, Paolino N, Eliasson AH, Shah AA, Holley AB (2011) Comparison of adjustable and fixed oral appliances for the treatment of obstructive sleep apnea. J Clin Sleep Med 7(5):439-445. doi: $10.5664 /$ jcsm. 1300

5. Serra-Torres S, Bellot-Arcis C, Montiel-Company JM, MarcoAlgarra J, Almerich-Silla JM (2015) Effectiveness of mandibular advancement appliances in treating obstructive sleep apnea syndrome: a systematic review. Laryngoscope. doi:10.1002/lary.25505

6. Oral appliances for obstructive sleep apnea: an evidence-based analysis (2009). Ontario health technology assessment series 9;(5):1-51

7. Fransson AM, Tegelberg A, Leissner L, Wenneberg B, Isacsson G (2003) Effects of a mandibular protruding device on the sleep of patients with obstructive sleep apnea and snoring problems: a 2year follow-up. Sleep Breath 7(3):131-141. doi:10.1007/s11325003-0131-7

8. Johal A, Fleming PS, Manek S, Marinho VC (2015) Mandibular advancement splint (MAS) therapy for obstructive sleep apnoea-an overview and quality assessment of systematic reviews. Sleep Breath 19(3):1101-1108. doi:10.1007/s11325-015-1148-4
9. Lim J, Lasserson TJ, Fleetham J, Wright J (2006) Oral appliances for obstructive sleep apnoea. Cochrane Database Syst Rev 1, CD004435. doi:10.1002/14651858.CD004435.pub3

10. Qaseem A, Holty JE, Owens DK, Dallas P, Starkey M, Shekelle P, Clinical Guidelines Committee of the American College of $\mathrm{P}$ (2013) Management of obstructive sleep apnea in adults: a clinical practice guideline from the American College of Physicians. Ann Intern Med 159(7):471-483. doi:10.7326/0003-4819-159-7201310010-00704

11. Vecchierini MF, Attali V, Collet JM, d'Ortho MP, El Chater P, Kerbrat JB, Leger D, Monaca C, Monteyrol PJ, Morin L, Mullens E, Pigearias B, Meurice JC (2015) A custom-made mandibular repositioning device for obstructive sleep apnoea-hypopnoea syndrome: the ORCADES study. Sleep Med. doi:10.1016/j. sleep.2015.05.020

12. Bloch KE, Iseli A, Zhang JN, Xie X, Kaplan V, Stoeckli PW, Russi EW (2000) A randomized, controlled crossover trial of two oral appliances for sleep apnea treatment. Am J Respir Crit Care Med 162(1):246-251. doi:10.1164/ajrccm.162.1.9908112

13. Rose E, Staats R, Virchow C, Jonas IE (2002) A comparative study of two mandibular advancement appliances for the treatment of obstructive sleep apnoea. Eur J Orthod 24(2):191-198

14. Marklund M, Stenlund H, Franklin KA (2004) Mandibular advancement devices in 630 men and women with obstructive sleep apnea and snoring: tolerability and predictors of treatment success. Chest 125(4):1270-1278

15. Sharples LD, Clutterbuck-James AL, Glover MJ, Bennett MS, Chadwick R, Pittman MA, Quinnell TG (2015) Meta-analysis of randomised controlled trials of oral mandibular advancement devices and continuous positive airway pressure for obstructive sleep apnoea-hypopnoea. Sleep Med Rev 27:108-124. doi:10.1016/j. smrv.2015.05.003

16. Marklund M, Carlberg B, Forsgren L, Olsson T, Stenlund H, Franklin KA (2015) Oral appliance therapy in patients with daytime sleepiness and snoring or mild to moderate sleep apnea: a randomized clinical trial. JAMA Int Med 175(8):1278-1285. doi:10.1001 /jamainternmed.2015.2051

17. Martinez-Gomis J, Willaert E, Nogues L, Pascual M, Somoza M, Monasterio C (2010) Five years of sleep apnea treatment with a mandibular advancement device. Side effects and technical complications. Angle Orthod 80(1):30-36. doi:10.2319/030309-122.1

\section{Comment}

Although retrospective, this sizeable study makes a useful contribution to an ongoing area of debate. The popular trend is increasingly in favor of adjustable appliances despite a lack of adequate trial-based evidence. The findings of this report are that there is no difference between adjustable and non-adjustable oral appliances except, importantly, in terms of cost. These data are a reminder that evidence from well designed and adequately powered RCTs is still required. Until then, the case for the superiority of adjustable devices remains unproven and clinical guidelines should reflect this.Timothy QuinnellCambridge, UK 